\title{
PENGARUH METODE BERMAIN TERHADAP HASIL BELAJAR SENAM LANTAI ROLL BELAKANG PADA SISWA KELAS VIII SMP NEGERI 4 BENGKULU
}

\author{
Yeyen Sari \\ Penjas FKIP UNIB, e-mail: yeyensarinara@gmail.com \\ Dian Pujianto \\ Universitas Bengkulu \\ Bayu Insanistyo \\ Universitas Bengkulu
}

\begin{abstract}
Abstrak
Penelitian ini bertujuan untuk mengetahui peningkatan senam lantai roll belakang setelah diberikan penerapan latihan menggunakan metode bermain pada siswa kelas VIII.6 SMP Negeri 4 Bengkulu. Metode penelitian yang digunakan dalam penelitian ini adalah metode pre-eksperimental designs dengan desain penelitian one-group pretestposttest designs, yang dimana dalam melakukan penelitian menggunakan tes awal (pretest), memberikan perlakuan, dan melakukan tes akhir (posttest) pada sampel kelas VIII.6 yang dipilih secara purposive sampling dari keseluruhan populasinya kelas VIII. Hasil penelitian dari tes akhir diperoleh Rata-rata hasil belajar pada pretest 40.19 dan posttes 57.76 dengan persentase peningkatan $43.71 \%$. Berdasarkan data uji t yang dilakukan maka didapatkan nilai $t_{\text {hitung }}$ sebesar 6.66. dengan demikian nilai $t_{\text {hitung }}=$ 6.66 lebih besar dari nilai $t_{\text {tabel }}=1.69$, artinya terdapat pengaruh metode bermain terhadap hasil belajar senam lantai roll belakang pada siswa kelas VIII SMP Negeri 4 Bengkulu.
\end{abstract}

Kata kunci : Metode Bermain, Senam Lantai , Roll Belakang.

\begin{abstract}
This study aims to determine the increase of roll back floor gymnastics after being given the practice of using the method of playing on the students of class VIII.6 SMP Negeri 4 Bengkulu. The research method used in this research is pre-experimental design method with one-group pretest-posttest designs, which in conducting the research using pretest, giving treatment, and performing posttest test on class VIII sample 6. selected by purposive sampling of the overall population of class VIII. Result of research from final test obtained Average learning outcomes in pre test 40.19 and post test 57.76 with percentage increase $43.71 \%$. Based on t test data that is done then obtained t_count value of 6.66. thus the value of $t_{-}$hitung $=6.66$ is greater than the value of t_table $=1.69$, it means there is influence of play method on learning of backstroke roll gymnastics at grade VIII student of SMP Negeri 4 Bengkulu.
\end{abstract}

Keywords: play method, roll floor, gymnastics 


\section{PENDAHULUAN}

Pendidikan jasmani merupakan bagian yang integral dari system pendidikan nasional secara keseluruhan. Pendidikan jasmani merupakan proses pendidikan yang memanfaatkan aktifitas jasmani yang direncanakan secara sistematis yang bertujuan untuk mengembangkan aspek kesehatan, kebugaran jasmani, keterampilan berpikiran kritis, serta pembiasaan pola hidup sehat yang bermuara untuk meransang pertumbuhan dan perkembangan kualitas fisik dan psikis yang seimbang. Seperti yang dikemukakan oleh Annarino, Cowell, dan Hazelton dalam Sukintaka (2004:16) yang menyatakan bahwa pendidikan jasmani merupakan pendidikan lewat aktifitas jasmani untuk mencapai tujuan pendidikan jasmani yang telah dirumuskan dalam ranah fisik, psikomotorik, afektif, dan kognitif.

Senam merupakan salah satu jenis olahraga yang sering diterapkan untuk meningkatkan kebugaran jasmani. Senam terdiri dari enam macam yaitu senam artistic, senam ritmik, senam akrobatik, senam aerobic, senam trampoline, dan senam umum. Senam lantai merupakan salah satu bagian dari enam macam kelompok senam diatas, Senam lantai termasuk ke dalam kelompok senam artistik. Senam lantai terbagi kedalam unsur gerakan yang bersipat statis (diam ditempat) dan dinamis (berpindah tempat). Keterampilan yang bersipat statis meliputi: kayang, sikap lilin, splits, berdiri dengan kepala, berdiri dengan kedua tangan dan sebagainya. Sedangkan keterampilan senam lantai yang bersipat dinamis meliputi: guling depan, guling belakang, meroda, dan lain sebagainya.

Roll belakang adalah gerakan menggulingkan badan yang dilakukan diatas matras ke arah belakang dalam posisi badan tetap membulat, kaki dilipat, lutut ditempelkan di dada, dan kepala ditundukkan sampai dagu melekat di dada. Roll belakang merupakan bentuk aktivitas jasmani yang kaya akan gerakan, cukup rumit dan komplek, sehingga dari pengamatan dan pengalaman penulis minat siswa mengenai pembelajaran senam lantai sedikit sekali dibandingkan pembelajaran bola besar seperti futsal dan basket, masih banyak siswa yang mengalami kesulitan dalam melakukan gerakan senam lantai Roll belakang, siswa dalam mengikuti pembelajaran terkesan menoton, metode pembelajaran tidak bervariasi, kemudian masih banyak siswa yang tidak bisa menggulingkan badannya kebelakang yang diakibatkan karena lemahnya kekuatan otot lengan untuk membantu tolakan, masih banyaknya siswa yang menggulingkan badan tidak lurus yang diakibatkan kurangnya keseimbangan antara tangan yang satu dengan yang lainnya, masih banyak siswa yang dalam gerakan masih kaku serta takut dalam menggulingkan badan yang diakibatkan kurangnya kelenturan serta mental anak dalam melakukan gerakan. tujuan dari penelitian ini adalah untuk mengetahui ada tidaknya pengaruh metode bermain terhadap hasil belajar senam lantai Roll belakang.

\section{METODE}

Metode yang digunakan adalah eksperimen. Bentuk penelitian yang digunakan dalam penelitian ini adalah pre-eksperimental designs. Menurut 
Sugiyono (2006:82) "bentuk preeksperimen designs ada beberapa macam yaitu : one-shot case study, one-group pretest-posttest designs, dan intact-group comparison. Dari ketiga bentuk tersebut, maka peneliti memilih model one-group pretest-posttest designs. Yaitu melakukan tes yang dimana terdiri dari dua tes, yaitu pretest yang berfungsi untuk mengungkapkan kondisi awal siswa sebelum memperoleh pembelajaran senam lantai roll belakang melalu metode bermain, selanjutnya yaitu posttest untuk mengetahui adakah peningkatan siswa setelah diberi perlakuan, agar bisa memberi gambaran kepada peserta didik bahwa ada pengaruh bermain terhadap pembelajaran roll belakang.

\section{HASIL DAN PEMBAHASAN}

1. Hasil Penelitian

1) Deskripsi Data

Setelah melakukan dan pengambilan data penelitian yang berjudul "pengaruh metode bermain terhadap hasil belajar senam lantai roll belakang pada siswa kelas VIII SMP Negeri 4 Bengkulu, dengan melakukan pretest dan posttest terhadap kemampuan melakukan gerakan senam lantai roll belakang pada siswa, maka dapat diperoleh data sebagai berikut :

Tabel 4 : Hasil Tes Awal Senam Lantai Roll Belakang Siswa Kelas VIII.6

\begin{tabular}{l|l|l} 
No & $\begin{array}{l}\text { Deskripsi } \\
\text { Statistik }\end{array}$ & Jumlah \\
\hline 1 & $\begin{array}{l}\text { Nilai } \\
\text { maksimum }\end{array}$ & 97 \\
\hline 2 & $\begin{array}{l}\text { Nilai } \\
\text { minimum }\end{array}$ & 20 \\
\hline 3 & $\begin{array}{l}\text { Rata-rata } \\
\text { (mean) }\end{array}$ & 40.19
\end{tabular}

\begin{tabular}{l|l|l}
4 & $\begin{array}{l}\text { Standar } \\
\text { deviasi }\end{array}$ & 21.88 \\
\hline 5 & Varians & 426.83
\end{tabular}

Gambar 5.

Diagram Batang Tes Awal (Pretest)

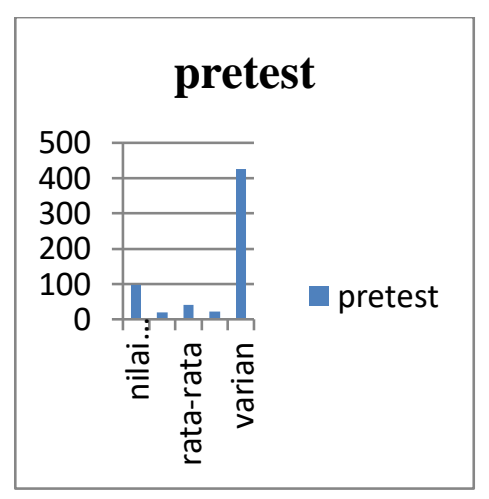

Tabel 5 : Hasil Tes Akhir Senam Lantai Roll Belakang Siswa Kelas VIII.6

\begin{tabular}{l|l|l} 
No & $\begin{array}{l}\text { Deskripsi } \\
\text { Statistik }\end{array}$ & Jumlah \\
\hline 1 & $\begin{array}{l}\text { Nilai } \\
\text { maksimum }\end{array}$ & 100 \\
\hline 2 & $\begin{array}{l}\text { Nilai } \\
\text { minimum }\end{array}$ & 23 \\
\hline 3 & $\begin{array}{l}\text { Rata-rata } \\
\text { (mean) }\end{array}$ & 57.76 \\
\hline 4 & $\begin{array}{l}\text { Standar } \\
\text { deviasi }\end{array}$ & 29.75 \\
\hline 5 & Varians & 776.73
\end{tabular}

Gambar 6.

Diagram Batang Tes Akhir (Postest)

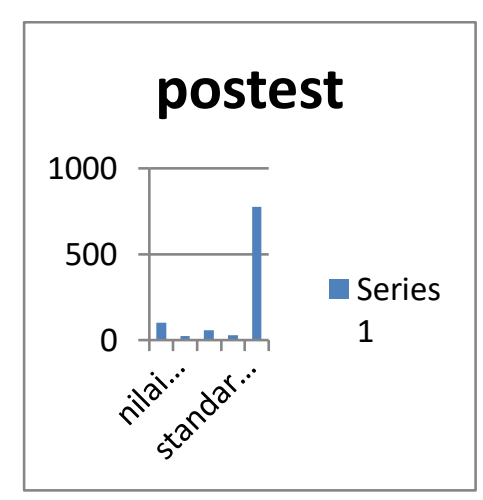


Gambar 7.

Diagram Batang Tes Awal dan Tes

Akhir

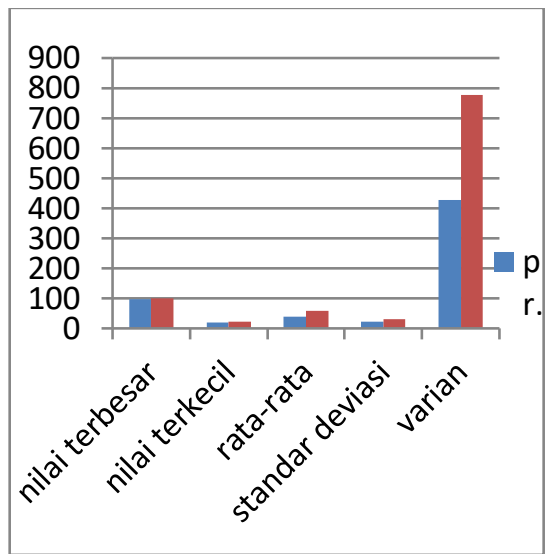

\section{Pembahasan}

Penelitian ini bertujuan untuk melihat ada atau tidaknya pengaruh yang diberikan perlakuan metode bermain terhadap hasil belajar senam lantai roll belakang. penelitian ini menggunakan teknik purposive sampling untuk mengambil sampel yang akan dijadikan penelitian. Desain penelitian yang digunakan dalam penelitian ini adalah one group pretestposttest design. Instrument penelitian ini menggunakan rubrik penilaian yang sudah di sahkan oleh dosen yang bersangkutan atau berpengalaman terhadap senam lantai.

Dari hasil pre-test dan post-test yang telah diolah datanya terdapat peningkatan kemampuan anak yang sebelumya sedikit bisa melakukan setelah diberi perlakuan jumlah anak yang bisa melakukan bertambah dengan hasil persentase penambahan sebesar $43.71 \%$ dari persentasi awal yang semula hanya $18.19 \%$.

Berdasarkan hasil pengujian hipotesis yang telah dilakukan sebelumnya menyatakan bahwa ada pengaruh yang signifikan dari metode bermain terhadap hasil belajar senam lantai roll belakang. Sehingga jika metode bermain ini terus di berikan setiap pembelajaran senam lantai roll belakang maka semangkin baik juga nilai siswa yang mencapai ketuntasan dalam pembelajaran. Dari ketiga metode bermain yang digunakan untuk meningkatkan hasil belajar senam lantai roll belakang, ketiga metode ini sangat besar pengaruhnya, karena dengan memberikan metode bermain maka anak akan sangat antusias dalam mengikuti pembelajaran, hal ini sama halnya dengan yang dikemukakan dalam teori rekreasi dalam Soemitro (1992:8) menjelaskan bahwa orang bermain didasarkan oleh pemikiran bahwa manusia membutuhkan bermain sebagai usaha untuk mengembalikan gairah hidup. Sehingga dengan bermain akan mampu meningkatkan serta mengembangkan berbagai aspek baik dari kognitif, afektif, dan psikomotor siswa. dari ketiga metode yang diberikan ada satu metode bermain yang sangat disukai dan dianggap menarik perhatian anak untuk terus melakukannya, yaitu metode bermain estafet menggunakan bola. Alasan kenapa metode ini bisa menjadi sangat menarik untuk meningkatkan hasil belajar anak, karena dalam metode ini terdapat unsur perpaduan antara permainan yang mereka sukai yaitu dengan bantuan bola. Bantuan bola yang didalamnya terdapat unsur bermain sangat baik diterapkan dalam pembelajaran senam lantai roll belakang, Karena semangkin anak tertarik dengan metode yang diberikan maka akan semangkin baik hasil yang akan anak dapatkan. 


\section{PENUTUP}

\section{Simpulan}

Berdasarkan hasil penelitian dan analisis uji pengaruh yang telah dilakukan maka dapat disimpulkan bahwa terdapat pengaruh metode bermain terhadap hasil belajar senam lantai roll belakang pada siswa kelas VIII.6 SMP Negeri 4 Bengkulu. Rata-rata hasil belajar pada pre test 40.19 dan post tes 57.76 dengan persentase peningkatan $43.71 \%$. peningkatan kemampuan tersebut merupakan pengaruh dari proses pemberian perlakuan metode bermain pada pembelajaran senam lantai yang dilakukan,

Berdasarkan data uji $t$ yang dilakukan maka didapatkan nilai $t_{\text {hitung }}$ sebesar 6.66. dengan demikian nilai $t_{\text {hitung }}=6.66$ lebih besar dari nilai $t_{\text {tabel }}=1.69$, artinya terdapat pengaruh metode bermain terhadap pembelajaran senam lantai roll belakang pada siswa kelas VIII SMP Negeri 4 Bengkulu.

\section{Saran}

Berdasarkan hasil penelitian yang telah diuraikan sebelumnya maka penelitian memberikan saran diantaranya sebagai berikut :

1) Diharapkan bagi tenaga pendidik agar bisa menggunakan metode bermain pada pembelajaran senam lantai agar bisa mendapatkan hasil yang diinginkan dan siswa bisa dengan mudah mencapai nilai ketuntasan karena metode bermain sangat la penting untuk diberikan, dengan alasan pada proses pembelajaran senam biasanya siswa terkesan monoton dan lebih dominan ingin bermain.
2) Diharapkan untuk para siswa agar bisa mengikuti pembelajaran dengan baik, karena pembelajaran senam lantai roll belakang biasanya selalu digunakan dan dipelajari pada tiap jenjang pendidikan.

3) Bagi penelitian lain, disarankan agar dapat membuat latihan yang tepat untuk meningkatkan pengaruh yang lebih besar untuk siswa.

\section{DAFTAR FUSTAKA}

Abdullah, Arma dan Agus Manadji. (1994). Dasar-Dasar Pendidikan Jasmani. Jakarta: Proyek Pembinaan dan Peningkatan Mutu Tenaga Kependidikan.

Agus, Mahendra. (2001). Pembelajaran Senam di Sekolah Dasar. Jakarta: Departemen Pendidikan Nasional

Aqib, Zainal, dan Ali Murtadlo. (2016). Kumpulan Metode Pembelajaran. Bandung: PT Sarana Tutorial Nurani Sejahtera.

Asep, Jihad dan Abdul Haris (2013) Evaluasi Pembelajaran. Yogyakarta: Multi Presindo. Hal 14.

Edwan. (2017). Pengaruh Metode Latihan Plyometric terhadap Kemampuan Jumping Smash Bola Voli Siswa Ekstrakurikuler SMPN 1 Bermani Ilir. Bengkulu: Universitas Bengkulu.

Pujianto, Dian. (2004). Pengaruh Senam Lansia terhadap Tekanan Darah dan Denyut Nadi Para Lansia di Dusun Sermo. Yogyakarta. Universitas Negeri Yogyakarta. 
Sugiyono. (2006). Metode Penelitian Kuantitatif Kualitatif dan $R$ \& $D$. Bandung: Alfabeta, cv.

Tangkudung, James. (2012). Kepelatihan Olahraga Pembinaan Prestasi Olahraga. Jakarta: Cerdas jaya ,(2016).Macam-macam Metodologi Penelitian. Jakarta: Lensa Media Pustaka Indonesia 